\title{
Word stress and sentence prosody in Greek
}

\author{
Antonis Botinis ${ }^{1}$, Christina Alexandris ${ }^{2}$, Athina Kontostavlaki ${ }^{1}$ \\ ${ }^{1}$ Laboratory of Phonetics and Computational Linguistics, National and Kapodistrian \\ University of Athens, Greece \\ ${ }^{2}$ Department of German Language and Literature, National and Kapodistrian \\ University of Athens, Greece
}

\begin{abstract}
The present study concerns the prosodic structure of Greek as a function of word stress and focus as well as statement and yes/no question sentence type distinctions. It is argued that the word stress distinction has a local domain whereas focus, statement and question distinctions have a global domain. Word stress has a lengthening effect on all segmental constituents of the stressed syllable and especially on vowel in combination with an intensity increase whereas the tonal pattern is variable in accordance with the global context. The focus distinction has no lengthening effect locally and may show variable tonal patterns locally and globally depending on the global context. The statement and yes/no sentence type distinction has variable prosodic patterns locally and globally and shows multiple interactions with variable focus applications.
\end{abstract}

Keywords: word stress, sentence prosody, intonation, statement, question, Greek

\section{Introduction}

This is a study of word and sentence prosody if Greek as a function of word stress, focus and statement vs. question sentence type distinctions. Word stress in Greek has a distinctive function and may be applied in one of the three last syllables in a lexical word whereas function words are usually unstressed (trisyllabic constraint). Any type of word in Greek, irrespective of its length or the combination of morphemes in compound structures, may have only one word stress (monotonic principle). Focus may be applied in any lexical word, most usually coinciding with word stress. However, in contrastive or corrective functions, focus may be applied in any syllable of lexical or function words in principle, even unstressed ones. Statements and yes/no questions in Greek do not differ in any linguistic aspect but prosody and focus may be applied in a similar way in both types of sentences.

The prosodic structure of word stress, focus and sentence type distinctions have been investigated (e.g. Botinis 1989, Themistocleous 2011, Botinis, Chaida, Nikolaenkova, Nirgianaki 2016) and this is a follow up study (Botinis, Kontostavlaki., Nikolaenkova., Themistocleous). In the present study, the acoustic correlates of word stress and focus as a function of statement vs. yes/no question sentence types are investigated.

Proceedings ExLing 2020: $11^{\text {th }}$ International Conference of Experimental Linguistics, 12-14 October, Athens, Greece 


\section{Methodology}

The speech material consists of one series of questions-answers and another series of questions-questions interactive dialogues. In the question-answer context, one speaker puts a question e.g. [pça ðu'levi sti 'madova]? (who works in Madova?) and the other speaker answers [i me'lina du'levi sti 'madova] (Melina works in Madova). In the question-question context, the same speaker puts a double question e.g., the first question [pça ðu'levi sti 'madova]? is followed by the second question [i me'lina du'levi sti 'madova]? In this way, the answer to the question-answer speech material can directly compared with the second question of the double question one.

Six female speakers at their twenties from the University of Athens produced the speech material two series in a normal tempo. All speakers speak standard Athenian Greek and none of them had any history of language disorders. The experimental task had no difficulties and all speakers produced the speech material without any particular effort.

The speech material was recorded in a soundproof room at the University of Athens. A Zoom $\mathrm{H} 4 \mathrm{n}$ audio recorder was used, and the recordings were coded as single mono sounds (sampling frequency: $22050 \mathrm{~Hz}$ ) and transferred to a PC for further analysis using a compact SD card. Tokens were typed in Standard Greek orthography. Test materials were manually segmented and labelled by using simultaneous inspections of waveforms and wide-band spectrograms (see Figures)

\section{Results}


Discussion 


\section{References}

Botinis, A. Stress and Prosodic Structure in Greek. 1989. Lund: Lund University Press.

Botinis, A., Chaida, A. Nikolaenkova, O., Nirgianaki, E. 2016. Intonation and polar questions in Greek revisited. In Botinis, A. (Ed.), Proc. ExLing 2016, 41-44.

Botinis, A. Kontostavlaki, A., Nikolaenkova, O., Themistocleous, Ch. 2019. Tonology and sentence structure in Greek. In Botinis, A. (Ed.), Proc. ExLing 2019, 29-32.

Themistocleous Ch. 2011. Prosody and Information Structure in Greek (in Greek). PhD Thesis, University of Athens. 